\title{
Fuzzy Relational Model to Establish Credit Worthiness of Sacco Members in Kenya
}

\author{
Makokha Ahmed Siro \\ Researcher \\ Jomo Kenyatta University of \\ Agriculture and Technology, Main \\ Campus, \\ P. O. Box $62000-00200$, \\ Nairobi, Kenya
}

\author{
Dennis Njagi, PhD \\ Supervisor \\ Jomo Kenyatta University of \\ Agriculture and Technology, Main \\ Campus, \\ P. O. Box $62000-00200$, \\ Nairobi, Kenya
}

\author{
Calvins Otieno, $\mathrm{PhD}$ \\ Supervisor \\ Jomo Kenyatta University of \\ Agriculture and Technology, Main \\ Campus, \\ P. O. Box $62000-00200$, \\ Nairobi, Kenya
}

\begin{abstract}
Credit scoring has provided a number of financial institutions like banks, Microfinance institutions the means of determining if a given client will default or repay their debt obligation. Credit defaulting has become a stubborn enemy to the financial sector globally. With numerous Saccos in Kenya today it is challenging to predict accurately the trust of its members hence there arise a need of models, which will determine Sacco members credit worthiness. Qualitative output variable (i.e. member credit worth) measured using factors (i.e. Credit Duration, Concurrent Credits, Repayment Amount, Most Valuable Asset and Account Balance with Sacco) are scaled using appropriate linguistic terms and fused using hierarchical sensory fusion to evaluate credit worth of Sacco members in Kenya. Similarly, the output variable member credit worthiness was assigned linguistic terms of Excellent, Good, Fair/ Average, Bad and Poor.
\end{abstract}

\section{Keywords}

credit worthiness, qualitative measures and fuzzy relations.

\section{INTRODUCTION}

\subsection{Background of the Study}

Fuzzy Logic systems are unique because they are able to handle numerical data and linguistic data simultaneously [1]. Hence fuzzy logic systems can be created to determine the credit score of Sacco members. Membership functions can be used to map numerical scores and linguistic data to obtain a numerical value that represents the credit score of a credit applicant. Systems designed and developed using Fuzzy Logic have shown to be more efficient than those based on conventional approaches [2]. Measuring fuzzy variables that are qualitative in nature is complex. A credit score is a numeric value that defines a member's ability to honour his or her credit terms. Many other Sacco's in Kenya, employ human judgmental approach to determine their members credit score. This approach is characterised with biasness that often than not lead to poor financial risk decisions.

The theory of fuzzy set is generally an extension of the ordinary set theory an approach which is useful when examining a number of real-world problems. The method in its ideal form presented by Zadeh allows an element to have only a degree of membership which can range from non-membership at degree 0 to full-membership at 1 . This gradation gives fuzzy logic features that enable it deal with the vagueness and ambiguities associated with real-world problems. It's this distinct methodology that allows fuzzy logic to deal with qualitative variables often encountered in a number of applications like credit scoring

\subsubsection{Credit Scoring}

Factors associated with credit are, in which money is not availed until all requirements are honoured. These requirements ensures the security and collateral are acquired before the credit is disbursed to the borrower. If these controls are weak, the credit process integrity can be weakened and abused. Thus, credit controls are vital in management of credit to ensure that Saccos have proper documentation, collateral and guarantees.

After the credit assessment and disbursement is done, the borrower is expected to pay back the credit as per the repayment instalment schedule. Each lending institution has a different repayment mechanism. Based on the specifics of the Sacco, customers can pay weekly, bi-weekly or monthly instalments ENON (2015). In order to ensure good repayment, Saccos have to ensure proper monitoring and follow up actions. According to [3] and [4], a number of the bottle necks like slow processing speed, long paper work queues associated with credit can be avoided by loan supervision, supervision help keeping good loan. It may take the form of visiting borrower's premises to investigate the general state of affairs and maintenance of plant and equipment. Also, to be observed is the state of employee morale and the physical stock of materials and finished goods. The general business policy and advice is considered. If the Sacco is to harmonize business development it has to review its own credit and loan policies as well as advising its customers. Again, keeping track of deposits and balances gives clue to the affair of the borrower

\subsection{Problem Statement}

A major problem often faced by lenders is failure by borrowers to pay back and has been echoed in the works of both researchers and practitioners. A number of methodologies in the form of credit score models that span both classical and contemporary timelines have already been developed to help evade this eminent predicament. Despite major advancement towards credit scoring model development and their accuracy, the use of models in actual practice is still a challenge. This uptake is attributed to the number of computational methods currently developed, Neural Networks, Bayesian Networks and Genetic Algorithms operating in a black box manner making it difficult for users to have basic understanding of the system [5]. The approach makes the model developer at least the only one knowledgeable about the operation of the system which consequently shuns off third party users. This can further be explained by the steepness of the learning curve required to learn the operations of system, a fact that has been pointed out 
as a major limitation of current computational models [6]. The problem even becomes magnified in cases where such models must be used by less formal creditors like Sacco's which have members that may be less knowledgeable of the computational complexity that comes with jargon linked to the various methods. In addition, majority of the developed models are calibrated for more established financial institutions like banks and microfinance organizations and can't be directly used by Sacco's which serve different a client base.

\subsection{Justification}

Fuzzy logic directly uses member ship functions which can be directly learned from the data. When the memberships functions have been adjusted, they directly provide a degree of membership for each of the inputs and how they relate to the outputs. By so doing, fuzzy logic directly by passes the limitations associated with other methods previously pointed and hence justifying its usage in the development of white box credit worth model

Fuzzy Logic Systems are simple to understand and are easily adaptable mainly because they use if then rules with simple words (linguistic variables). The use of linguistic variables describes values in a way that close to the way humans think like very good, very bad. This particular feature (linguistic variables) associated with fuzzy logic makes it simpler to understand consequently have a less stepper learning curve.

The features combined enable fuzzy logic not only to provide a simple solution but also enable it to provide a solution which can easily be understood. Together, these features enable the development of system that can easily be adopted by less formal creditors hence justifying its usage for Sacco's.

\subsection{Significance of the Study}

Several studies have been done on fuzzy logic credit scoring models. Fuzzy relational systems represent an alternative to rule based systems preserving their qualitative characteristics (i.e. can be interpreted by IF-THEN statements like fuzzy rule based systems) but avoid the need for hard-work rules development [7], Fuzzy relational systems can be used to evaluate qualitative data and determine credit worth. In line with the current state of knowledge presented by [8] this research will contribute a novel fuzzy system for accessing credit worth models for Sacco's. The developed system will be an alternative method to the current rudimentary techniques [4] used by Sacco's for assessing the credit potential of clients.

To the Sacco's in Kenya the credit worth model developed by this research presents a much simpler, accurate and less timeconsuming approach for assessing credit worth of potential clients. In so doing, Sacco's will significantly reduce the risk associated with extending credit to bad creditors which will go a long way in improving their financial stance.

\subsection{Main Objective}

This study aims at adopting a Fuzzy Relational Model to Establish Credit Worthiness of Sacco Members in Kenya.

\subsection{Specific objectives}

i. To study credit worth models.

ii. To adopt a fuzzy model to establish the credit worth of Sacco members in Kenya.

iii. To develop the fuzzy model to establish the credit worth of Sacco members in Kenya.

\subsection{Research Question}

i. What research has been conducted on credit worth models?

ii. How can fuzzy relation model be used to establish credit worth of Sacco members in Kenya?

iii. How will the fuzzy model for establishing the credit worth of Sacco members in Kenya be developed?

\subsection{Proposed Solution for the Study}

All critical parameters of credit scoring are represented qualitatively hence complex to include in quantitative models. To overcome this problem this research develops a model of evaluating qualitative variables using fuzzy relation. Previous studies have developed models that measure capacity of repayment, The qualitative factors that will be used to determine Sacco members credit score in this study are Creditability, Account Balance, Credit Duration (month), Credit History Purpose, Credit Amount, Share Capital, Membership Period, Repayment Amount, Guarantors, Duration in Current Address, Most Valuable Available Asset, Age (years), Concurrent Credits, Type of Apartment, No of Credits with Sacco, Net Pay, No of Dependents, Telephone. This will involve data analysis, using collected data to inform the inputs to the developed model and generating the overall model for the study.

\section{LITERATURE REVIEW}

\subsection{A Review of Fuzzy Credit Score Models}

In the field of credit score modelling a number of models have been developed. According to [9] credit rating lies in the top of problems in finance. According to the author Egyptian banks are not able to predict the credit worth of clients with a great degree of accuracy. The presented a fuzzy logic model that could be used for predicting the credit score for different bank clients. The study used inputs parameters such as ability to pay back, profitability, operational ability in order to predict the credit potential of the different clients. In his conclusion, he identifies fuzzy logic as one the most significant techniques in the field of machine learning especially since it's reliable, scalable and stable

[10] The research found that, Fuzzy Logic is effective in modelling applications where human judgement is involved and could therefore be used in evaluating loan applications. However, the choice of variables, especially thresholds can make the model less useful if economic conditions change in the future unless the variables are adjusted. In his study he recommended that variables must be selected such that they are significant enough so that they have a contribution of outputs given a firing strength

[11] Thinking about which factors are the most important and which should be used for the modelling is the most important step. One major drawback is the time and skill needed to form the fuzzy rule base. It takes a considerable amount of energy to skim through data to determine the relations between the different variables and formulate the rules. In his study he recommended proper rule reduction methods should be used if time and energy are to be saved when developing a given rule base.

[9] The proposed model in this paper has proven its effectiveness in predicting the credit risk rating of the commercial banks in advance with a reasonable accuracy. This paper also provides a set of financial indicators which can be used in the assessment of the bank credit risk rating. The results showed that Fuzzy logic is one of the most significant 
techniques in machine learning that are used to predict credit risk rating of commercial banks. The results also indicated that fuzzy logic technique is more scalable, reliable, stable, and different from classical methods. In his study he recommended that future work to integrate other machine learning techniques such as neural networks with the proposed model in order to enhance the accuracy of the model results.

[12] In this paper, a new credit scoring model is formulated by improving the FICO scoring method using the MCDM methods of AHP and TOPSIS. The decision makers' subjectivity in the assessment process is considered by incorporating fuzzy sets theory in the model. the new FICO model will be termed as a fuzzy AHP-TOPSIS hybrid, with the fuzzy AHP aspects being compared between two methods: CEA and MPM. The flexibility of the model improved such that the decision maker can easily modify the weights of the criteria under evaluation without disrupting the effectiveness and flow of the current FICO model. The robustness of the method allows decision makers to adapt their own rating system depending on the economic climate when the assessment is being carried out. The proposed fuzzy AHP-TOPSIS hybrid model can be programmed into a software package as a decision support tool for any lending institution. This could reduce the time required for a customer's loan application, and efficiency as a result of improved credit screening process could provide cost savings. Lastly, with the aid of the proposed decision support system, lending institution can spend more time in value-added activities, such as promoting ancillary products and services to targeted customers, rather than being caught in the process of loans approvals. In the long term, decision support systems may aid in reducing the risk owing to default payments. Although two types of fuzzy AHP methods have been included in this model, emphasis have been placed on MPM for calculating the weights over CEA. This is because CEA has a setback that may reduce the least important criterion to a weight of zero, which subsequently ignores the influence of that particular criterion in the total credit score of an applicant. Also, CEA provides poorer weight dispersion and may allow few criteria to be of same importance in the final ranking exercise of the credit scoring model. In addition, MPM presents a consistency index for the interval judgments which cannot be found in CEA.

[13] The granting microcredit process adopted by microfinance institution in Morocco includes some failures related to credit risk management, which essentially affects their financial stability. The decision to grant microcredit is based essentially on the judgment of the credit officer or the manager and on the results of the credit bureau consultation. The aim of this research is to set up a credit scoring model capable of predicting customer behaviour by exploiting fuzzy logic. This method allows to provide visibility on the behaviour of all customers by referring not only to statistical studies carried out beforehand but also to the opinion of the manager who is in direct contact with the customers. It should be noted that in this context, the result obtained is variable, since the classification of certain inputs varies over time, hence the need to update them or to add decision filters if necessary. He recommended the use of machine learning techniques since the statistical techniques are less accurate

\subsection{Research Gaps}

[9] research identifies the need to develop standard variables that need to be used for the development of a given fuzzy system. [10][13][13][13] Rule reduction methods need to developed and streamlined for all fuzzy logic systems [12] There is need to improve on the number of linguistic variables that are used alongside the different credit score models. [13]
There is need to develop more accurate machine learning technique.

[11] sited the need to use classifiers in combination so as to achieve a reasonable output which is more accurate. A major angle to pursue further research in credit scoring would be to automate scenario generation, which was treated procedurally through the sensitivity analysis section in this study. This calls for those who are in the case-based reasoning and meta-heuristic optimization to evaluate rule construction based on historical data as to predict future defaults, while accounting for the impact of those risks on the lending institution's reserve. In terms of MCDM, future researchers may perform credit scoring studies by comparing the model results with other MCDM models such as fuzzy VIKOR, fuzzy ELECTRE and fuzzy PROMETHEE

\section{PROPOSED DESIGN}

\subsection{Fuzzy Relational Model}

Fuzzy relations are often presented in the form of twodimensional tables. A $\mathrm{m} \times \mathrm{n}$ matrix represents a contented way of entering the fuzzy relation R. The different Fuzzy relations for the input variables are presented in the tables $1,2,3$ and 4 below.

Table 1: Fuzzy Relation R1 Between Most Valuable Asset and Repayment Amount (i.e. Repayment Capability)

\begin{tabular}{|c|c|c|c|c|c|}
\hline $\begin{array}{c}\text { Most Valuable } \\
\text { Asset/ Repayment } \\
\text { Amount }\end{array}$ & $\begin{array}{c}\text { Very } \\
\text { High }\end{array}$ & High & Medium & Low & $\begin{array}{c}\text { Very } \\
\text { Low }\end{array}$ \\
\hline Very High & 1 & 1 & 1 & 1 & 1 \\
\hline High & 1 & 1 & 1 & 1 & 0.8 \\
\hline Medium & 1 & 1 & 1 & 0.8 & 0.6 \\
\hline Low & 1 & 1 & 0.8 & 0.6 & 0.4 \\
\hline Very Low & 1 & 0.8 & 0.6 & 0.2 & 0.2 \\
\hline
\end{tabular}

The relationship R1 represents the fusion between the most valuable asset and repayment amount as can be seen in table 1 above. One's most valuable asset is a direct measure of how much they can stake inform of collateral. Therefore, someone with a very high asset value can get a very high loan and consequently have very high repayment amount. The strength of the relations is varied from 1 to 0 as required. The fuzzy relations degree of membership varies within the $x \in 1,0$ domain. For five levels of interaction, the peaks can be directly obtained by dividing the domain by the levels which effectively yields a 0.5 peak. As the asset value reduces so does the repayment amount one could also accrue reducing. A very low asset value would actually be rejected a scenario that is represented by a zero in the fuzzy relation. Therefore, fusing these two variables would directly represent one's capacity to repay.

The relationship R2 represents the fusion between the Credit Duration and Concurrent Credit as shown in the Table 2. The number of Concurrent Credit when combined together with Credit Duration yields a measure of one's credit reputation. Someone who takes a loan and repays it back on time can keep getting loans hence a higher number of concurrent current credits. Therefore, a high number of concurrent credits would directly coincide with clients who have longer durations of credit. The good repayment reputations of such clients directly enables them to directly bargain for longer repayment. However, clients who have very few concurrent credits may not 
be able to bargain for longer repayment periods since they have yet received sufficient reputation by the Sacco. If the number of concurrent credits are very low, then the repayment duration one could have is very low a scenario which would correspond to 0 on the fuzzy relation scale.

Table 2: Fuzzy Relation R2 Between Credit Duration and Concurrent Credit (i.e. Credit Reputation)

\begin{tabular}{|c|c|c|c|c|c|}
\hline $\begin{array}{c}\text { Credit Duration/ } \\
\text { Concurrent Credit }\end{array}$ & $\begin{array}{c}\text { Very } \\
\text { High }\end{array}$ & High & Medium & Low & $\begin{array}{c}\text { Very } \\
\text { Low }\end{array}$ \\
\hline Very High & 1 & 0.8 & 0.6 & 0.4 & 0.4 \\
\hline High & 1 & 0.8 & 0.6 & 0.4 & 0.4 \\
\hline Medium & 1 & 0.8 & 0.6 & 0.4 & 0.4 \\
\hline Low & 1 & 0.8 & 0.6 & 0.4 & 0.4 \\
\hline Very Low & 1 & 0.8 & 0.6 & 0.4 & 0.2 \\
\hline
\end{tabular}

The relationship R3 represents the fusion between R1 and R2 as shown in the table 3 . R1 directly measures a member's repayment capability whilst R2 directly measures member's credit reputation. The fuzzy relations shows that a high repayment capability would directly correspond to a high credit reputation. However, people who have low capacity to repay and also have low credit reputation will not be eligible for loans. The rules related to such clients can therefore be directly ruled out as observed in the table 3-3.

Table 3: Fuzzy Relation R3 Between R1 and R2 (i.e. Credibility)

\begin{tabular}{|c|c|c|c|c|c|}
\hline R1 / R2 & Very High & High & Medium & Low & $\begin{array}{c}\text { Very } \\
\text { Low }\end{array}$ \\
\hline Very High & 1 & 0.8 & 0.6 & 0.4 & 0.4 \\
\hline High & 1 & 0.8 & 0.6 & 0.4 & 0.32 \\
\hline Medium & 1 & 0.8 & 0.6 & 0.32 & 0.24 \\
\hline Low & 1 & 0.8 & 0.48 & 0.24 & 0.16 \\
\hline Very Low & 1 & 0.64 & 0.36 & 0.16 & 0.04 \\
\hline
\end{tabular}

The combination of R3 and Account Balance with Sacco directly yields to the credit worth of a member. The Account Balance with Sacco is a very key factor in this relation. Members with a very high Account Balance with Sacco will not take loans which directly eliminates the extremity in the relation. On the other hand, if R3 which compounds both Repayment Capability and Credit Reputation are low, then it can be directly inferred that such clients will not take on credit therefore such rules can therefore be considered to have low firing strength. A high Account Balance with Sacco would go long way in influencing the repayment as can be observed in the table 4 .

Table 4: Fuzzy Relation R4 Between R3 and Account Balance with Sacco (i.e. Credit Worth)

\begin{tabular}{|c|c|c|c|c|c|}
\hline $\begin{array}{c}\text { R3/ Account } \\
\text { Balance with } \\
\text { Sacco }\end{array}$ & $\begin{array}{c}\text { Very } \\
\text { High }\end{array}$ & High & Medium & Low & $\begin{array}{c}\text { Very } \\
\text { Low }\end{array}$ \\
\hline Very High & 1 & 0.64 & 0.36 & 0.16 & 0.08 \\
\hline High & 1 & 0.64 & 0.36 & 0.16 & 0.064 \\
\hline Medium & 1 & 0.64 & 0.36 & 0.128 & 0.048 \\
\hline Low & 1 & 0.64 & 0.288 & 0.096 & 0.032 \\
\hline Very Low & 1 & 0.512 & 0.216 & 0.064 & 0.08 \\
\hline
\end{tabular}

\subsection{Generation of Fuzzy Inputs and Output Variables}

The studies conducted by [14]-[17] confirm that behavioural factors are stronger predictors for credit risk. The five behavioural variables with the strongest correlation to the output will therefore be used as inputs for the fuzzy model and their impact is discussed below.

\subsubsection{Account Balance with Sacco}

This variable was chosen as a predictor variable mainly because it has been shown by researchers [9], [18] to have a direct effect on the capacity of a member to pay back. According to the latter author, a high account balance would represent a high source of income which would directly influence a member's ability to pay back.

\subsubsection{Credit Duration}

Credit Duration represents how long a member will have before repaying the Loan. Empirical results from different studies [19], [20] have shown that the Credit Duration a member has will directly influence their repayment habits. Members who have a long repayment period tend to repay back especially if manageable instalments are allowed to the members indicating a positive correlation between Credit Duration and member's credibility.

\subsubsection{Most Valuable Asset}

A member with many higher valued assets would represent a higher threshold income. However according to [21] this specific parameter can be subjective especially since it may be more representative of a member's spending behaviour. In which case, considering it as predictor variable can be misleading. The author recommends carrying out an ANOVA test to assess its influence on the credibility of a member. If the ANOVA identifies the variable as less significant hence it should automatically be rejected, otherwise it should be treated differently.

\subsubsection{Concurrent Credits}

The number of loans the member has is also a good indicator of whether they was able to repay a loan. According to [22] concurrent credits directly influence the credit rating of a member as it directly affects the liquidity of the member.

\subsubsection{Repayment Amount}

The amount that one has got to repay back is a measure of the financial burden. If the repayment amount as a ratio of the current income is too high, then there is a great chance the client will default. The repayment amount is therefore an important indicator of the member's financial burden and consequently their ability to repay back the loan. Studies on the 6c's [23] of credit score have shown that repayment amount can single individually influence the loan repayment ability of a member.

\subsubsection{Credit Worth}

Credit Worth of a Sacco member could be "poor", "Bad", "Fair/ Average", "Good" or "Excellent". The defuzzification process is responsible for converting the different output into linguistic terms. A weighted average method was used for the defuzzification process.

\section{RESULTS AND DISCUSSIONS}

\subsection{Variable Fuzzification}

The different linguistic terms used for quantifying the different inputs had to be converted to numerical values via triangular membership functions. For triangular membership functions the 
different linguistic variables can be converted to numerical values and vice versa via the function $\mathrm{f}(\mathrm{x})$ described in equation 1 below. Table 5 and 6 indicate the different values for the different triangular membership functions for each of the input and output variables.

$$
f(x, a, b, c)=\left\{\begin{array}{cc}
0, & x \leq a \\
\frac{x-a}{b-a}, & a \leq x \leq b \\
c-x & b \leq x \leq c \\
c-b, & c \leq x \\
0, &
\end{array}\right\}
$$

Table 5: Value for Triangular Membership Functions for Each of The Input Variables

\begin{tabular}{|c|c|c|}
\hline Input Variable & Linguistic Term & Range \\
\hline \multirow{5}{*}{ Repayment Amount } & Very Low & $1.0000-1.7500$ \\
\hline & Low & $0.9725-2.4930$ \\
\hline & Average & $2.0160-3.2210$ \\
\hline & High & $2.4910-4.0490$ \\
\hline & Very High & $3.3600-4.0000$ \\
\hline \multirow{5}{*}{ Most Valuable Asset } & Very Low & $1.0000-1.7500$ \\
\hline & Low & $1.0030-5.5250$ \\
\hline & Average & $2.0100-3.2300$ \\
\hline & High & $2.5000-4.0100$ \\
\hline & Very High & $3.2500-4.7500$ \\
\hline \multirow{5}{*}{ Credit Duration } & Very Low & $-13.0000-20.9800$ \\
\hline & Low & $4.0000-37.9900$ \\
\hline & Average & $21.0800-55.0000$ \\
\hline & High & $38.0100-72.0000$ \\
\hline & Very High & $55.0000-89.0000$ \\
\hline \multirow{5}{*}{ Concurrent Credits } & Very Low & $0.5000-1.5000$ \\
\hline & Low & $1.0000-2.0000$ \\
\hline & Average & $1.5000-2.5000$ \\
\hline & High & $2.0000-3.0000$ \\
\hline & Very High & $2.5000-3.5000$ \\
\hline \multirow{5}{*}{$\begin{array}{c}\text { Account Balance with } \\
\text { Sacco }\end{array}$} & Very Low & $0.2500-1.7500$ \\
\hline & Low & $1.0000-2.5000$ \\
\hline & Average & $1.7500-3.2500$ \\
\hline & High & $2.5000-4.0000$ \\
\hline & Very High & $3.2500-4.7500$ \\
\hline
\end{tabular}

Table 6: Membership Functions for The Output Variable

\begin{tabular}{|c|c|c|}
\hline Output Variable & Linguistic Term & Range \\
\hline \multirow{4}{*}{$\begin{array}{c}\text { Credit } \\
\text { Worthiness }\end{array}$} & Poor Credit Worth & $0.0000-0.3000$ \\
\cline { 2 - 3 } & $\begin{array}{c}\text { Bair/ Average Credit } \\
\text { Worth }\end{array}$ & $0.6290-0.6890$ \\
\cline { 2 - 3 } & Good Credit Worth & $0.6890-0.7190$ \\
\cline { 2 - 3 } & Excellent Credit Worth & $0.7190-1.0000$ \\
\hline
\end{tabular}

\subsubsection{Repayment Amount}

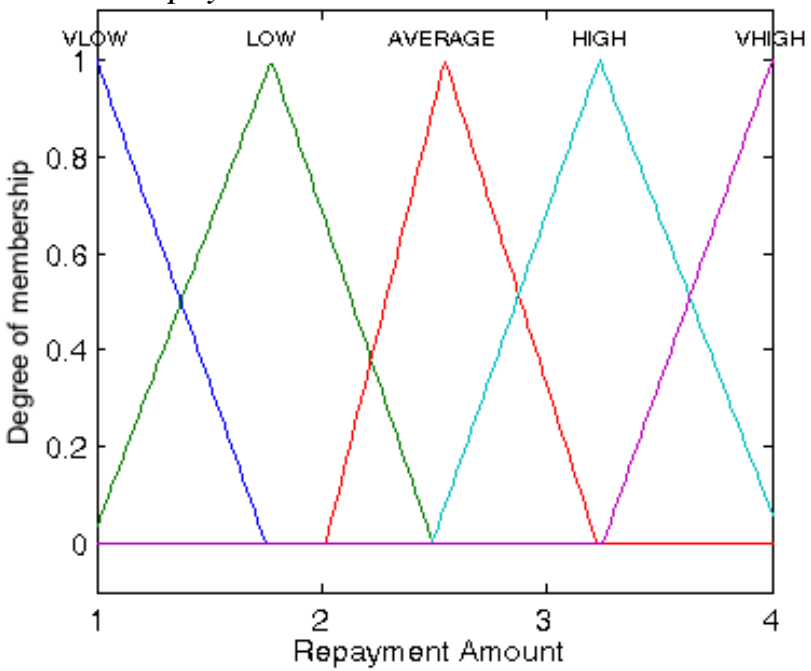

Fig 1:Trimf for Repayment Amount for Sacco Members in Kenya

According to [24] fuzzy set theory suggests that there is no one practiced method for determining the shape and width of a fuzzy membership function. It is a subjective process that will vary with the designer of the control system. All the linguistic variables were mapped to their corresponding data range and their corresponding membership functions plots were obtained. Fig 2 above shows the trimf plot for Repayment Amount measured propositionally from a scale of 1 to 4 . The Repayment Amount was found to range between 1 and 4 from the collected data. Basing on the input data range, the input was directly assigned a degree of membership. It means that a value submitted as 1.1 would automatically fall in the range of Very Low with a degree of membership of 0.8 . A value of 1.5 would have degree of membership of about 0.5 for the Very Low i.e. VLOW membership function and membership of 0.8 for the Low membership function. Which membership function fires is determined by the Fuzzy Aggregation Method.

\subsubsection{Most Valuable Asset}

The values for most valuable asset were also directly obtained from the data associated with the Most Valuable Asset. Fig 3 below shows the trimf plot for Most Valuable Asset with data ranging between 1 and 4 from the data collected. Basing on the input data range, the input was directly assigned a degree of membership. A value submitted as 1.1 would automatically fall in the range of Very Low with a degree of membership of 0.8 while a value of 1.5 would have degree of membership of about 0.5 for Very Low i.e. VLOW membership function and 
membership of 0.8 for the Low membership function. Which membership function fires is determined by the fuzzy aggregation method. Values submitted 1.7 and 2 would have $100 \%$ membership to the LOW Membership functions. It can also be directly inferred that values submitted as 2.5 would have multiple degrees of freedom to the Average, Low and High membership function. Membership functions like Low, High and Average which intersect with other membership functions directly indicate varying degrees of membership for the data values submitted to those membership functions

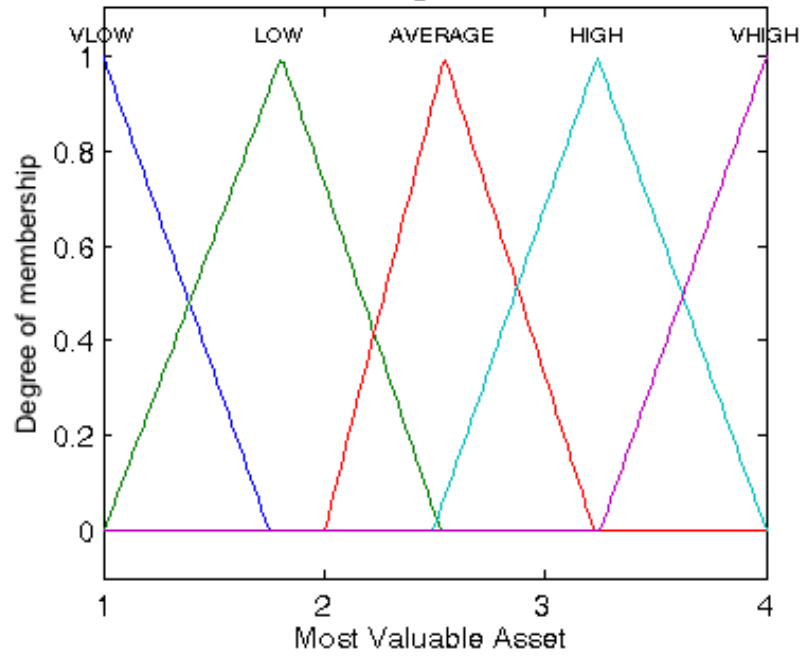

Fig 2: Trimf for Most Valuable Asset for Sacco Members in Kenya

\subsubsection{Credit Duration}

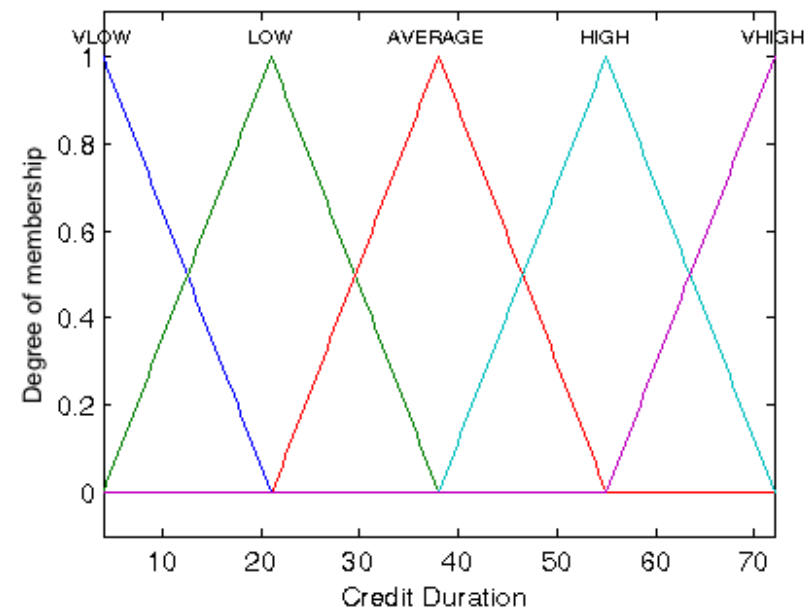

Fig 3: Trimf for Credit Duration for Sacco Members in Kenya

The values for Credit Duration were also directly obtained from the data associated with the Credit Duration. Fig 4 above shows the trimf plot for Credit Duration with data ranging between 0 and 72 months. Basing on the input data range, the input was directly assigned a degree of membership. It means that a value submitted as 3 months would automatically fall in the range of Very Low with a degree of membership of 0.8 while a value of 10 months would have degree of membership of about 0.5 for the Very Low i.e. VLOW membership function and membership of 0.8 for the Low membership function. Which membership function fires is determined by the fuzzy aggregation method. Different values submitted will have varying degrees of membership due to symmetry exhibited by the different membership functions.

\subsubsection{Concurrent Credits}

The values for number of Concurrent Credit were also directly obtained from the data associated with Sacco Members Concurrent Credits. Fig 5 below shows the trimf plot for number of Concurrent Credit with data ranging between 1 and 3 from the data collected. Basing on the input data range, the input was directly assigned a degree of membership. This implies that a value submitted as 0.4 would automatically fall in the range of Very Low with a degree of membership of 0.8 while a value of 1.4 would have a degree of membership of about 0.2 for Very Low i.e. VLOW membership function and membership of 0.8 for Low membership function. Which membership function fires is determined by the fuzzy aggregation method. Different values submitted will have varying degrees of membership due to symmetry exhibited by the different membership functions.

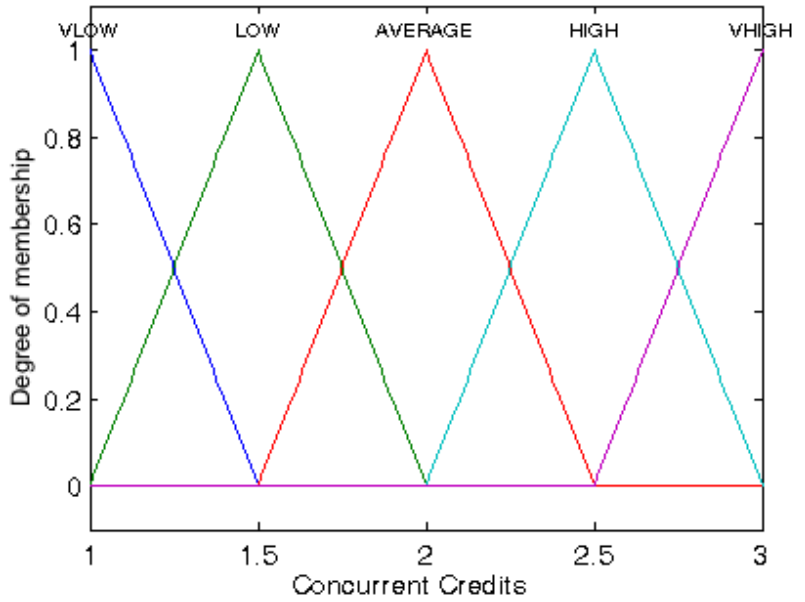

Fig 4: Trimf for Concurrent Credit for Sacco Members in Kenya

\subsubsection{Account Balance with Sacco}

The values for account balance with Sacco were also directly obtained from the data associated with the account balance with Sacco. Fig 6 below shows the trimf plot for account balance with Sacco had data ranging between 1 and 4 . Basing on the input data range, the input was directly assigned a degree of membership. Implying that a value submitted as 1.5 would automatically fall in the range of Very Low with a degree of membership of 0.32 while a value of 2 would have degree of membership of about 0.32 for average membership function and membership of 0.7 for Low membership function. Which membership function fires is determined by the fuzzy aggregation method. Different values submitted will have varying degrees of membership due to symmetry exhibited by the different membership functions. 


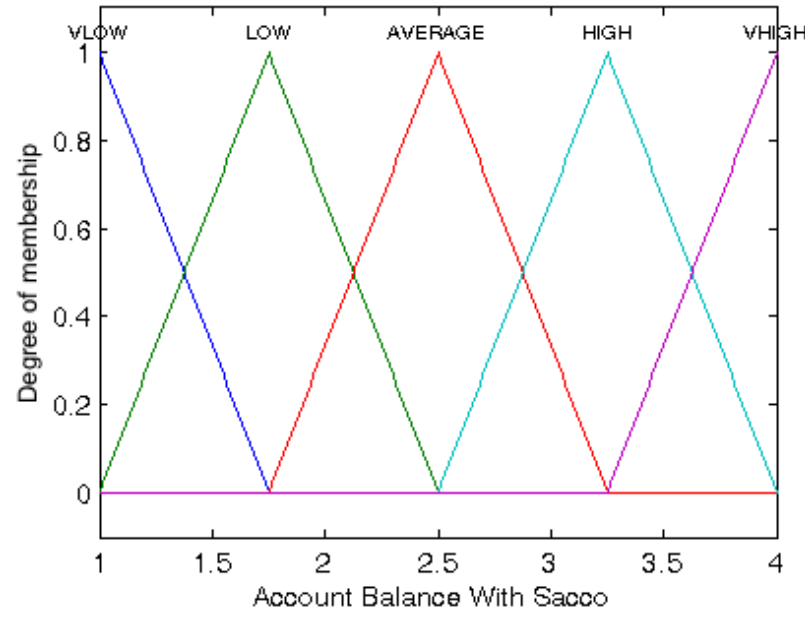

Fig 5: Trimf for Account Balance with Sacco for Sacco Members in Kenya

\subsubsection{Repayment Capability}

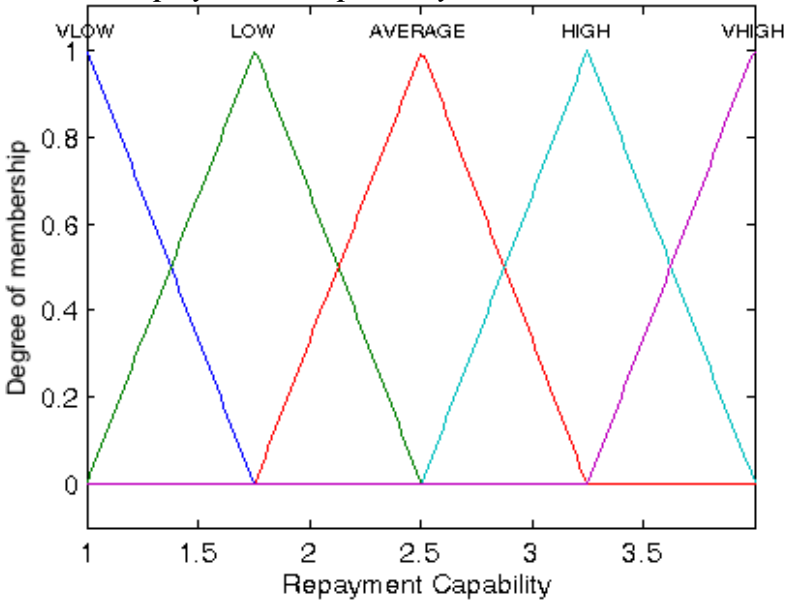

Fig 6: Trimf for Repayment Capability for Sacco Members in Kenya

The values for Repayment Capability were also directly obtained from the data associated with the Repayment Capability of Sacco members. Fig 7 above shows the trimf plot for Repayment Capability with data ranging between 1 and 4 as indicated in the data collected. Basing on the input data range, the input was directly assigned a degree of membership. It means that a value submitted as 1.5 would automatically fall in the range of Very Low with a degree of membership of 0.32 while a value of 2 would have degree of membership of about 0.32 for Average membership function and membership of 0.7 for Low membership function. Which membership function fires is determined by the fuzzy aggregation method. Different values submitted will have varying degrees of membership due to symmetry exhibited by the different membership functions.

\subsubsection{Credit Reputation}

The values for Credit Reputation were also directly obtained from the data associated with the Credit Reputation. Fig 8 below shows the trimf plot for Credit Reputation with data ranging between 1 and 4.5 from the data collected. Basing on the input data range, the input was directly assigned a degree of membership. It means that a value submitted as 1 would automatically fall in the range of very low with a degree of membership of 0.1 while a value of 1.5 would have degree of membership of about 0.3 for Very Low i.e. VLOW membership function and membership of 0.7 for the Low membership function. Which membership function fires is determined by the fuzzy aggregation method. The values close 2.75 will have $100 \%$ membership to the Average membership function as can be observed to the plot. Other membership functions will have members with varying degree of freedom since the membership functions intersect symmetrically.

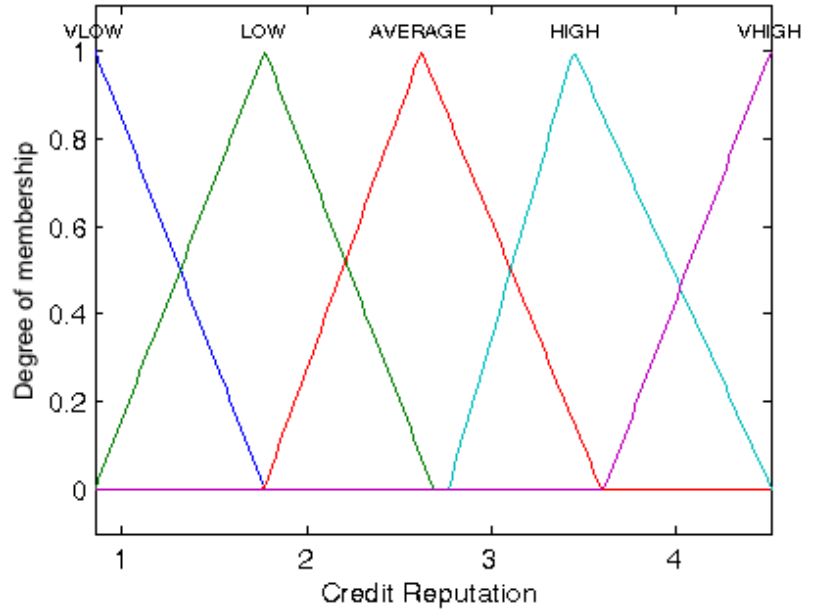

Fig 7: Trimf for Credit Reputation for Sacco Members in Kenya

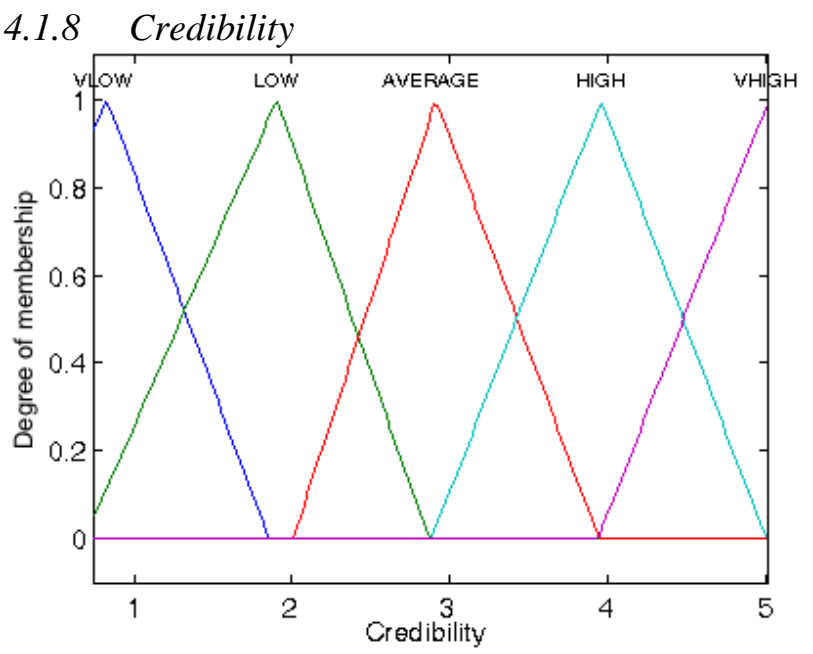

Fig 8: Trimf for Credibility for Sacco Members in Kenya

The values for Credibility were also directly obtained from the data associated with Sacco members Credibility. Fig 9 above shows the trimf plot for Credibility with data ranging between 1 and 5. Basing on the input data range, the input was directly assigned a degree of membership. It means that a value submitted as 1 would automatically fall in the range of Very Low with a degree of membership of 0.3 while a value of 1.5 would have degree of membership of about 0.3 for the Very Low i.e. VLOW membership function and membership of 0.6 for the Low membership function. Which membership function fires is determined by the fuzzy aggregation method. Values between 1.8 and 2.0 will have $100 \%$ degree of membership to the Low Membership function. Other membership functions will have membership with varying degree of freedom since the membership functions intersect symmetrically. 


\subsubsection{Credit Worthiness}

The final credit worth of a Sacco member was determined by combining the Credibility and the value of one's account balance with Sacco. The value for credibility was found to be 1.02 while average account balance with Sacco was 1.08544 . Credibility has values that lies between Very Low and Low side of the triangular membership function while Account Balance with Sacco has values that lies between Very Low and low side of the triangular membership function. Credibility of membership of 0.6 very low and 0.4 low while Account Balance with Sacco has a degree of membership of 0.7 Very low and 0.3 low. The rules that fired based on the input data as a result of fusion between Concurrent credit and Credit Duration is shown on table 7.

Table 7: Input Data as a Result of Fusion Between Credibility and Account Balance with Sacco

\begin{tabular}{|c|c|c|c|c|c|}
\hline $\begin{array}{c}\text { Credibility } \\
\text { / Account } \\
\text { Balance }\end{array}$ & $\begin{array}{c}\text { Very } \\
\text { Low }\end{array}$ & Low & Average & High & Very High \\
\hline Very Low & $\begin{array}{c}\text { Poor } \\
\text { credit }\end{array}$ & $\begin{array}{c}\text { Poor } \\
\text { Credit }\end{array}$ & $\begin{array}{c}\text { Poor } \\
\text { Credit }\end{array}$ & $\begin{array}{c}\text { Fair } \\
\text { Credit }\end{array}$ & Fair credit \\
\hline Low & $\begin{array}{c}\text { Poor } \\
\text { credit }\end{array}$ & $\begin{array}{c}\text { Poor } \\
\text { Credit }\end{array}$ & $\begin{array}{c}\text { Fair } \\
\text { credit }\end{array}$ & $\begin{array}{c}\text { Fair } \\
\text { Credit }\end{array}$ & $\begin{array}{c}\text { Fair } \\
\text { Credit }\end{array}$ \\
\hline Average & $\begin{array}{c}\text { Poor } \\
\text { credit }\end{array}$ & $\begin{array}{c}\text { Fair } \\
\text { credit }\end{array}$ & $\begin{array}{c}\text { Fair } \\
\text { credit }\end{array}$ & $\begin{array}{c}\text { Fair } \\
\text { credit }\end{array}$ & $\begin{array}{c}\text { Good } \\
\text { Credit }\end{array}$ \\
\hline High & $\begin{array}{c}\text { Fair } \\
\text { credit }\end{array}$ & $\begin{array}{c}\text { Fair } \\
\text { Credit }\end{array}$ & $\begin{array}{c}\text { Fair } \\
\text { Credit }\end{array}$ & $\begin{array}{c}\text { Good } \\
\text { Credit }\end{array}$ & $\begin{array}{c}\text { Good } \\
\text { Credit }\end{array}$ \\
\hline Very High & $\begin{array}{c}\text { Fair } \\
\text { Credit }\end{array}$ & $\begin{array}{c}\text { Fair } \\
\text { credit }\end{array}$ & $\begin{array}{c}\text { Good } \\
\text { credit }\end{array}$ & $\begin{array}{c}\text { Good } \\
\text { Credit }\end{array}$ & $\begin{array}{c}\text { Excellent } \\
\text { Credit }\end{array}$ \\
\hline
\end{tabular}

\section{ACKNOWLEDGEMENT}

\subsection{Study Conclusion}

This research has generated a Fuzzy Relation Framework that allows Sacco to establish the credit worth of their members. This allows them to reduce vagueness, uncertainty, and subjectivity. This research study has developed a framework that allows for the measurement of Repayment Capability and Credit Reputation of the different Sacco members. By the fusing the two parameters, this research has also directly developed a frame work for developing the Credibility that is associated with a given Sacco member

The research work generated a simple to use framework that will allow managers to use Fuzzy Relation concepts instead of judgemental and complex approaches for determining credit worth of Sacco members. Most credit score variables are subjective and qualitative in nature and hence difficult to incorporate into quantitative models. This research provides a framework for incorporating such qualitative credit score measures. It focused on Repayment Capability, Credit Reputation and Credibility which are very important measures of the credit worth of a given Sacco member

\subsection{Study Recommendations}

There is extreme subjectivity involved in the development of fuzzy models especially in determining the kind of membership functions to be used. As has been shown by this research great accuracy levels can be achieved. This research there recommends the use of a data driven model to set the parameters for the different membership functions.

Also, for the system to be used around the different Sacco's in Kenya, this research recommends user experience design. Even if the model has fully been developed, tested and validated, it's important that the different stake holders be given a chance to test the system, in that way their user experiences can be factored into the system. This can in turn result into an enriched user experience.

\subsection{Future Work}

Unlike Mamdani systems, Sugeno Fuzzy inference systems extremely powerful but are dependent on the nature of training data that is used. Therefore, it's important that a system that automatically trains itself be developed. In this way new data variations that come to light especially due to variability in the population can be directly incorporated. This can in turn lead to a system that can be used with less system training for a long period of time. Lastly further research needs to be conducted on the relationship between Repayment Capability, Credit Reputation and Credibility as factors that determine the credit worth of credit applicant.

\section{REFERENCES}

[1] K. Bart, Neural Networks and Fuzzy Systems: A Dynamical Systems Approach to Machine Intelligence. 1992.

[2] V. Kecman, Learning And Soft Computing - Support Vector Machines, Neural Networks, and Fuzzy Logic Models. London, England: Massachusetts Institute of Technology, 1948.

[3] K. Otieno, R. Mugo, D. Njeje, and A. Kimathi, "Effect of Corporate Governance on Financial Performance of SACCOS in Kenya," Res. J. Financ. Account., vol. 6, no. 2, pp. 390-407, 2015.

[4] F. N. Nkuru, "Factors Affecting Growth of Saccos Within the Agricultural Sector In Kenya: A Case Of Meru Farmers Saccos," vol. 4, no. 1, pp. 34-45, 2015.

[5] H. Jiang, W. Ching, K. Fai, C. Yiu, and Y. Qiu, "Stationary Mahalanobis Kernel SVM for Credit Risk Evaluation," Appl. Soft Comput., 2018.

[6] L. Dirick, G. Claeskens, and B. Baesens, "Time to default in credit scoring using survival analysis: a benchmark study,” J. Oper. Res. Soc., 2016.

[7] P. . Costa Branco and J. . Dente, "A Fuzzy Relational Identification Algorithm and Its Application to Predict The Behaviour of A Motor Drive System.," Fuzzy Sets Syst., 2000.

[8] F. Louzada and G. B. Fernandes, "Classification methods applied to credit scoring: A systematic review and overall comparison," 2018.

[9] N. R. Darwish and A. S. Abdelghany, "A Fuzzy Logic Model for Credit Risk Rating of Egyptian Commercial Banks," Int. J. Comput. Sci. Inf. Secur., vol. 14, no. 2, pp. 11-19, 2016.

[10] U. Farouk Ibn Abdulrahman, J. Kobina Panford, and J. Ben Hayfron-Acquah, "Fuzzy Logic Approach to Credit Scoring for Micro Finance in Ghana: A Case Study of KWIQPLUS Money Lending,” Int. J. Comput. Appl., vol. 94, no. 8, pp. 11-18, 2014.

[11] S. Sampath and V. Kalaichelvi, "Assessment of Mortgage Applications Using Fuzzy Logic,” Int. J. Econ. Manag. Eng., vol. 8, no. 11, pp. 3487-3491, 2014.

[12] J. Ignatius, A. Hatami-Marbini, A. Rahman, L. Dhamotharan, and P. Khoshnevis, "A Fuzzy Decision 
Support System for Credit Scoring," Neural Comput. Appl., vol. 29, no. 10, pp. 921-937, May 2018.

[13] G. Bennouna and M. Tkiouat, "Fuzzy logic approach applied to credit scoring for micro finance in Morocco," Procedia Comput. Sci., vol. 127, pp. 274-283, 2018.

[14] G. A. C. Xiao Yao 爪, Jonathan Crook, "Support vector regression for loss given default modelling," Expert Syst. Appl., vol. 37, no. 1, pp. 127-133, 2014.

[15] S. D. Volpone, S. Tonidandel, D. R. Avery, and S. Castel, "Exploring the Use of Credit Scores in Selection Processes: Beware of Adverse Impact," J. Bus. Psychol., 2015.

[16] G. Road, "Lending Organization and Credit Supply During the 2008 - 2009 Crisis," vol. 9999, no. 9999, pp. 1-29, 2017.

[17] P. Danenas and G. Garsva, "Selection of Support Vector Machines Based Classifiers for Credit Risk Domain," Expert Syst. Appl., vol. 42, no. 6, pp. 3194-3204, 2015.
[18] O. Amat, R. Manini, and M. A. Renart, "Credit concession through credit scoring: Analysis and application proposal," Intang. Cap., vol. 13, no. 1, pp. 51-70, 2017.

[19] J. M. Mwangi, "( Saccos ) in Financial Intermediation in Nairobi County,” no. October, 2011.

[20] H. Bierman and W. H. Hausman, "The Credit Granting Decision," Manag. Sci., vol. 16, no. 8, p. B-519--B-532, Apr. 1970.

[21] D. Björkegren and D. Grissen, "Behavior Revealed in Mobile Phone Usage Predicts Loan Repayment," pp. 1-28, 2015.

[22] R. Calabrese, "Downturn Loss Given Default: Mixture Distribution Estimation,” Eur. J. Oper. Res., vol. 237, no. 1, pp. 271-277, 2014.

[23] M. G. Kavussanos and D. A. Tsouknidis, "Default Risk Drivers in Shipping Bank Loans," Transp. Res. Part E Logist. Transp. Rev., vol. 94, pp. 71-94, Oct. 2016.

[24] F. Dernoncourt, Introduction to fuzzy logic. MIT, 2013. 